\title{
A green step towards computing: Green cloud computing
}

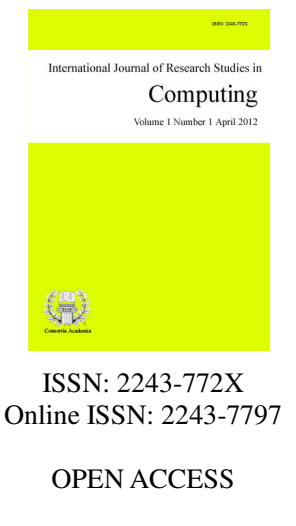

Garg, Preeti $\$

MIET, Meerut, India (preeti.itgarg@gmail.com)

\section{Abstract}

Due to the exponential growth of internet, Cloud Computing came into existence. Cloud computing describes highly scalable computing resources supplied as an outer service through internet on pay-as-usability basis. Mobile Cloud Computing refers to an infrastructure where data processing and storage can happen away from mobile device. These both computing need large data stores to process the users request, these data stores emit a huge amount of carbon and consume a lot of power which gave birth to Green cloud computing. Green cloud computing is the new era of cloud computing. It is an effective way of cloud computing that guarantees green and pollution free environment with least energy consumption and greener environment. The objective of this paper is to explore the concept of Green Cloud Computing and why do we need green cloud and most importantly how green cloud is different from cloud computing and mobile cloud computing and how it is more advantageous than cloud computing. Here architecture of Green cloud computing is also proposed.

Keywords: cloud computing; mobile cloud computing; green cloud; computing; cloud; mobile user; carbon emission 


\section{A green step towards computing: Green cloud computing}

\section{Introduction}

\subsection{Cloud computing}

Cloud computing is one of the most emerging technology in the field of Information technology. Cloud computing is a model of information processing, storage, and delivery in which physical resources are provided to clients on demand. Instead of purchasing actual physical devices, servers, storage, or any networking equipment, clients lease these resources from a cloud provider as an outsourced service (Qureshi, Ahmad, Rafique, \& Islam, 2011). Cloud computing provides Cloud Computing enables users to elastically utilize resources in an on-demand fashion. More or less Cloud computing describes highly scalable computing resources supplied as an outer service through internet on pay-as-usability basis (Garg \& Sharma, 2013).

The main call for Cloud computing is that user only utilizes what they required and only pay for what they really use. The cloud computing provides a remote architecture where the users can remotely access services, applications and data storage. One has to only establish account with Cloud Service Providers like Amazon Web Server, Simple Storage Services (S3), Elastic Cloud (EC2), Google maps etc. Cloud computing provides three key capabilities (1) Elasticity (2) Pay by Use (3) Self-service. Elasticity can be said as illusion of infinite resources. You can start your application with one server and the resources can be increased on demand. Pay by Use is subscribing and unsubscribing the IT infrastructure. It is just like subscribing the TV channels on demand and unsubscribing when not required. Self Service means that the end user does not require any intermediary entity to configure the resources.

\subsection{Mobile Cloud Computing}

Mobile cloud computing is a technique or model in which mobile applications are built, powered and hosted using cloud computing technology. Mobile Cloud Computing is a service that allows resource constrained mobile users to adaptively adjust processing and storage capabilities by transparently partitioning and offloading the computationally intensive and storage demanding jobs on traditional cloud resources by providing ubiquitous wireless access (Hoang, Chonho, Dusit, \& Wang, 2011).

Aepona (2010) describes MCC as a new paradigm for mobile applications whereby the data processing and storage are moved from the mobile device to powerful and centralized computing platforms located in clouds. Mobile device does not need to have large storage capacity and powerful CPU speed because cloud computing applications go via a browser. All data processing is performed outside the mobile devices on a centralized computing platform located in clouds. A mobile cloud approach enables developers to build applications designed specifically for mobile users without being bound by the mobile operating system and the computing or memory capacity of the Smartphone. Mobile cloud computing is using cloud computing through your mobile devices. So it is a relation between cloud computing and mobile web. The areas where mobile cloud can be used are (1) Multimedia search (2) Image Processing (3) Crowd Computing (4) Natural Language Processing. Through mobile cloud, the multimedia searching could be executed in context of nearby phones available. Mobile cloud computing can be used in processing images to extract their meaning.

\subsection{Green Cloud Computing}

The term combines the words green -- meaning environmentally friendly -- and cloud, the traditional symbol for the Internet and the shortened name for a type of service delivery model known as cloud computing (Garg, \& Buyya, 2011). Green Computing means the eco-friendly use of computer resources. In broader terms, it is also 
A green step towards computing: Green cloud computing

defined as the study of designing, manufacturing/engineering, using and disposing of computing devices in a way that reduces their environmental impact. It environmentally and eco- friendly uses the computers and their resources. Many IT manufacturers and developers are continuously investing in developing and designing energy efficient computing devices for the betterment of the environment and to reduce the usage of harmful material. They are more encouraging for recyclability of digital devices and papers.

This paper is organized in many sections. Section 2 of this paper defines the characteristics of cloud computing. Section 3 describes the various advantages of cloud computing. Section 4 shows the impact of using cloud over the environment. Section 5 explains that why do we need green cloud. Section 6 describes the architecture of cloud computing and green cloud computing. Section 7 differentiate the cloud, mobile cloud and green cloud computing and finally conclusion and future research work in Section 8.

\section{Cloud computing characteristics}

There are various characteristics of Cloud Computing which are described as follows:

$>$ On-demand self-service: The user can easily demand the resources and server's time as needed without any interception in the services provided. User has to pay for the services used on pay per use basis.

$>$ Broad Network Access: The programmer can efficiently configure the applications of cloud computing on mobile phones, laptops and PDA's. The cloud computing provides heterogeneous computing platform.

$>\quad$ Resource Pooling: Here resources are available for multiple users and users can use these resources. The location of resource is hidden from the user thus it gives a high level of abstraction.

$>\quad$ Rapid elasticity: The rapid elasticity allows users to quickly scale in and scale out any interception in processing of the application. The resources can be demanded in any amount at any time at any place.

$>$ Measured Services: Cloud computing provides monitoring over the resource utilization as it automatically optimizes the resources based on the type of the services. It provides transparency between the provider and user.

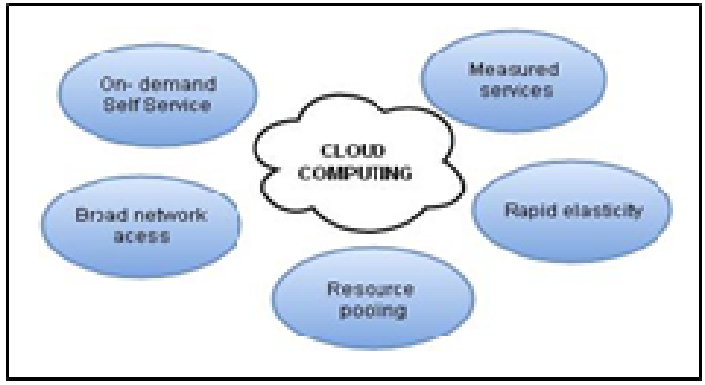

Figure 1. Cloud computing characteristics

\section{Significance of Cloud Computing}

Cloud computing has a number of advantages:

$>$ Resource virtualization: Cloud computing provides the virtualization of the infrastructure from business services. Thus the user has no idea about the location of the resources he is using.

$>\quad$ Pay-per-use and self-service: Users do not need to install any software in their own device. He/she can use any service provided by the client and can pay on the basis of his/her usage. 
$>$ Flexibility: The cloud computing provides flexibility to choose vendors. There are a number of vendors and a number of services provided by them. We can easily choose any vendor according to our requirements.

Elasticity of resources: It is the biggest advantage of cloud computing. There are a lot of resources available on the cloud. We can use any resource we need and can release them at any time.

> Cost reduction: This factor influences the investors to go for cloud computing. As there is no need for capital investment to start the development.

\section{Cloud impact on the environment}

Cloud Computing is using data centers for storing and processing the user's data. These data centers are very expensive as well as are very unfriendly to the environment. Carbon emission due to data centers is increasing day by day. Our country is embossing carbon more than Argentina and Netherland. High energy is needed to power and cool these huge servers hosted in data centers which is the biggest reason of carbon emission. According to a report IT industry contributes $2 \%$ of total carbon emission which is increasing day by day. So there is a need to control this carbon emission and this can be done by moving a step towards Green cloud.

According to IDC (International Data Corporation) report, the global IT Cloud services spending is estimated to increase from $\$ 16$ billion in 2008 to $\$ 42$ billion in 2012, representing a compound annual growth rate (CAGR) of 27\% (Garg \& Buyya, 2011). Attracted by this growth prospects, Web-based companies (Amazon, eBay, Salesforce.com), hardware vendors (HP, IBM, Cisco), telecom providers (AT\&T, Verizon), software firms (EMC/VMware, Oracle/Sun, Microsoft) and others are all investing huge amount of capital in establishing Cloud data-centers (Garg \& Buyya, 2011).

\section{Need for green cloud}

With the rise in the internet speed over decade there is an alarming increase in the thousands of e-commerce transactions and web based queries. This increase in demand is been handled by the large-scale data-centers which consolidates different data-structure for storage, cooling, and network systems. But the business organizations have paid a huge amount to maintain these data-centers and the servers and also it is very time consuming. So with the emergence of cloud computing one is able to overcome all these difficulties.

Cloud computing describes highly scalable computing resources supplied as an outer service through internet on pay-as-usability basis. Users do not need to install any software in their own device; they can use any software or platform available through the cloud. Users can also store their data at cloud rather than storing it on their own computers. For these reasons people need cloud. But as many users are using cloud for their purposes, we need large data centers, which emit a lot of energy that can be harmful for the environment. So using green cloud can help the environment.

Cloud computing requires a heavy consumption of energy. Today, typical data-centers with 1000 racks need 10 Megawatt of power to operate (Rivoire \& Kozyrakis, 2007), which results in higher operational cost. In addition, in April 2007, Gartner estimated that the Information and Communication Technologies (ICT) industry generates about $2 \%$ of the total global $\mathrm{CO}_{2}$ emissions, which is equal to the aviation industry (Rivoire \& Kozyrakis, 2007). According to a report published by the European Union, a decrease in emission volume of $15 \%-30 \%$ is required before year 2020 to keep the global temperature increase below $2{ }^{\circ} \mathrm{C}$ (Garg, \& Buyya, 2011). Thus, energy consumption and carbon emission is a concerned topic for the environment. It is been estimated that some data-centers will make efficient energy consumption by using techniques like virtualization and work load consolidation. Contrary to the above opinion, some studies, for example Greenpeace (Greenpeace International, 2010), observe that the Cloud May give rise to problems like global warming and carbon 
A green step towards computing: Green cloud computing

emissions. Hence finally green cloud framework is recommended for reducing carbon emissions in efficient manner without compromising over the quality of services provided by the multiple cloud service providers.

\subsection{Cloud Computing Architecture}

Cloud Computing provides SaaS (Software as a Service), IaaS (Infrastructure as a Service) and Paas (Platform as a Service) services to the users.

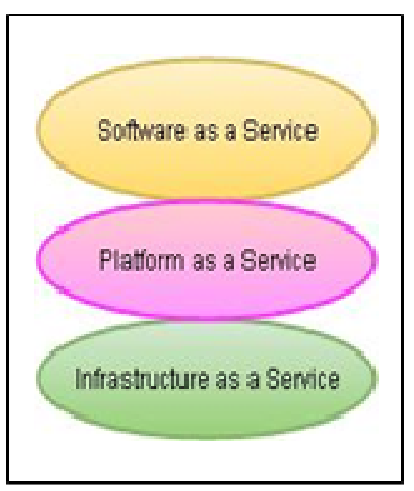

Figure 2. Cloud Computing Architecture

$>\quad$ Infrastructure as a Service (IaaS): IaaS enables the provision of storage, hardware, servers, and networking components. The client typically pays on a per-use basis. Examples of IaaS are Amazon Elastic Cloud Computing and Simple Storage Service (S3).

$>\quad$ Platform as a Service (PaaS): It offers an advanced integrated environment for building, testing, and deploying custom applications. The examples of PaaS are Google App Engine, Microsoft Azure, and Amazon, Map Reduce/Simple Storage Service.

$>\quad$ Software as a Service (SaaS): It supports a software distribution with specific requirements. In this layer, the users can access an application and information remotely via the Internet. Salesforce is one of the pioneers in providing this service model. Microsoft's Live Mesh also allows sharing files and folders across multiple devices simultaneously (Garg \& Sharma, 2013).

\subsection{Green Cloud Computing Architecture}

In Green Cloud Computing Architecture there are there entities involved: The users or a company, Green Broker and Public Private Clouds. Green broker works as an interface between these. The task of middleware is to manage the services between the cloud and the client with the least carbon emission and least power consumption. The middleware is composed of a user interface application and a windows service (Hulkury \& Doomun, 2012). The Functions of Green Broker are:

Layer 1: Cloud Request Services: This layer analysis the requirements of the users and provide the services to the client on their request. Actually it offers the cloud to the clients.

$>\quad$ Layer 2: CO2 Analysis Services: This layer calculates the cost and carbon footprints of services. The carbon emitted by the data centers is calculated by this layer.

$>$ Layer 3: Scheduling and Monitoring: The work of this layer is to establish the green policies. It performs the carbon aware scheduling. 


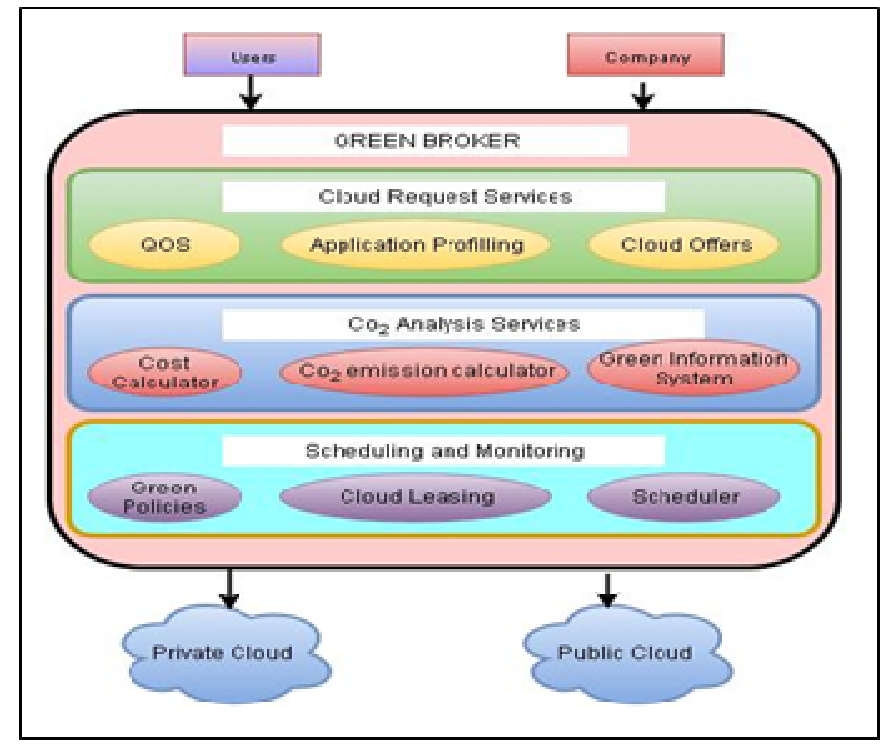

Figure 3. Green Cloud Computing Architecture

\subsection{Differences between Cloud, Mobile Cloud and Green Cloud Computing}

\section{Table 1}

\section{Difference}

\begin{tabular}{|c|c|c|}
\hline Cloud Computing & Mobile Cloud Computing & Green Cloud Computing \\
\hline $\begin{array}{l}\text { In this we have IaaS, PaaS, SaaS, IaaS } \\
\text { provides monitoring, accessing and } \\
\text { managing data centers. PaaS is used for } \\
\text { the application development and thirdly } \\
\text { SaaS represent the largest cloud market } \\
\text { growing quickly. }\end{array}$ & $\begin{array}{l}\text { In this we have mobile devices } \\
\text { and cloud providers. } \\
\text { Users can use the facility of } \\
\text { clouds using their mobile } \\
\text { devices like mobile phones etc. }\end{array}$ & $\begin{array}{l}\text { In this we have green middleware } \\
\text { and green broker. The green cloud } \\
\text { middleware provide the client a } \\
\text { tool to better manage the } \\
\text { distribution of tasks to cloud with } \\
\text { the least carbon emission (i.e. least } \\
\text { power consumption) and other } \\
\text { relevant decision criteria (Hulkury } \\
\& \text { Doomun, 2012) }\end{array}$ \\
\hline $\begin{array}{l}\text { Cloud computing is designing and } \\
\text { building hardware for processing } \\
\text { various information and data through } \\
\text { data centers. }\end{array}$ & $\begin{array}{l}\text { It is a service that allows } \\
\text { resource constrained mobile } \\
\text { users to adaptively adjust } \\
\text { processing and storage } \\
\text { capabilities by transparently } \\
\text { partitioning and offloading the } \\
\text { computationally intensive and } \\
\text { storage demanding jobs on } \\
\text { traditional cloud resources by } \\
\text { providing ubiquitous wireless } \\
\text { access (Garg \& Sharma, 2013). }\end{array}$ & $\begin{array}{l}\text { Green cloud computing is defined } \\
\text { as the study of designing and } \\
\text { engineering using of computing } \\
\text { devices in a way which reduces } \\
\text { the environmental impact. }\end{array}$ \\
\hline $\begin{array}{l}\text { Data centers hosting cloud computing } \\
\text { applications consumes huge amount of } \\
\text { energy which contributes to the carbon } \\
\text { footprints to the environment and } \\
\text { increase operational cost }\end{array}$ & $\begin{array}{l}\text { In mobile cloud computing } \\
\text { also we are using cloud so } \\
\text { there is high carbon emission } \\
\text { which effect the environment }\end{array}$ & $\begin{array}{l}\text { Green cloud computing reduces } \\
\text { the carbon footprints, save energy } \\
\text { and reduces operational cost. }\end{array}$ \\
\hline
\end{tabular}




\section{Conclusion and future work}

The concept of cloud computing provides a great opportunity to users to utilize their services by on-demand basis. But the energy efficiency of cloud computing become the most private issue. Integrated green cloud architecture with green middleware enables minimum energy consumption to private or public cloud. Clouds are essentially Data Centres hosting application services offered on a subscription basis. However, they consume high energy to maintain their operations. Clouds have high operational cost and huge impact on the environment so a carbon Aware Green Cloud Framework is used to improve the carbon footprint of Cloud computing. A lot of research is under process for maximizing the efficiency of Green Data Centers and Developing Regions to benefit the most. In future the work can be done on energy efficiency of cloud, making these more efficient and to calculate the carbon emission.

\section{References}

AEPONA. (2010). White paper on mobile cloud computing solution brief. AEPONA.

Baliga, J., Ayre, R. W. A., Hinton, K., \& Tucker, R. S. (2014). Green cloud computing: Balancing energy in processing, storage, and transport. Proceedings of the IEEE, 99(1), 149-167. http://dx.doi.org/10.1109/JPROC.2010.2060451

Chu, F. S., Chen, K. C., \& Cheng, C. M. (2011). Toward green cloud computing. Seoul, Korea: ACM. http://dx.doi.org/10.1145/1968613.1968651

Cisco. (2009). Cisco visual networking index: Forecast and methodology, 2009-2014 white paper. Retrieved from http://www.cisco.com

Doukas. C., Pliakas, T., \& Maglogiannis, T. (2010) Mobile healthcare information management unitizing cloud computing and android OS. In the Annual International Conference of the IEEE on Engineering in Medicine and Biology Society (EMBC) (pp. 1037-1040). IEEE.

Garg, P., \& Sharma, V. (2013). Secure data storage in mobile cloud computing. International Journal of Scientific \& Engineering Research, 4(4), 1154-1159.

Garg, S. K., \& Buyya, R. (2011). Green cloud computing and environmental sustainability.

Greenpeace International. (2010). Make IT green. Retrieved from http://www.greenpeace.org/international/en/publications/reports/make-it-green-Cloudcomputing

Harjani, B. M., \& Gopalan, S. M.(2013). Comparative study between green cloud computing and mobile cloud computing. International Journal of Scientific and Research Publications, 3(3), 1-4.

Hoang, T. D., Chonho, L., Dusit N., \& Wang P. (2011). A survey of mobile cloud computing: architecture, applications, and approaches. Wireless Communication \& Mobile Computing, 13(18), 1587-1611.

Hulkury, M. N., \& Doomun, M. R. (2012). Integrated green cloud computing architecture. In Proceedings of international conference on advanced computer science applications and technologies. Retrieved from https://arxiv.org/ftp/arxiv/papers/1212/1212.1284.pdf http://dx.doi.org/10.1109/acsat.2012.16

Khan, A. N., Kiah, M. L., Khan S. U., \& Madani, S. A. (2012). Towards secure mobile cloud computing: A survey. Future Generation Computer Systems, 29(5), 1278-1299. http://dx.doi.org/10.1016/j.future.2012.08.003

Nimje, A. R., Gaikwad, V. T., \& Dati, H. N. (2013). Green cloud computing: A virtualized security a virtualized security framework for green cloud computing. International Journal of Advanced Research in Computer Science and Software Engineering, 3(4), 642-646.

Qureshi, S. S., Ahmad, T, Rafique, K., \& Islam, S. (2011). Mobile cloud computing as future for mobile applications - Implementation methods and challenging issues. In the Proceedings of IEEE CCIS2011 (pp. 15-17). http://dx.doi.org/10.1109/ccis.2011.6045111

Rivoire, S., S., Shah, M. A., Ranganathan, P., \& Kozyrakis, C. (2007). A balanced energy-efficiency benchmark. In the Proceedings of the 2007 ACM SIGMOD: International Conference on Management of Data (pp. 365-376). NY, USA 
Garg, P. 
